\title{
A Reliability Framework for the Student Learning Process
}

\author{
Joanne S. Utley (Corresponding author) \\ School of Business and Economics, North Carolina A\&T State University \\ 1601 E. Market St. , Greensboro, NC, USA \\ Tel: 336-285-3390Ｅ-mail: sulekj@ncat.edu \\ Rhonda L. Hensley \\ School of Business and Economics, North Carolina A\&T State University \\ 1601 E. Market St. , Greensboro, NC, USA \\ Tel: 336-285-3360Ｅ-mail: hensleyr@ncat.edu
}

Received: November 29, 2012

Accepted: December 11, 2012

Online Published: December 12, 2012

doi:10.5430/jbar.v1n2p120

URL: http://dx.doi.org/10.5430/jbar.v1n2p120

\begin{abstract}
This paper proposes and illustrates an analytical framework for improving the reliability of the student learning process. The proposed framework combines systems thinking with technical tools for error reduction. Data from an undergraduate quantitative methods class were used to analyze student performance. Results of this analysis suggested several failsafe solutions for error reduction. Implementation of these failsafe methods improved class participation and performance.
\end{abstract}

Keywords: Service reliability, Student learning process, Error reduction

\section{Introduction}

No student really wants to repeat a course due to a failing grade. Likewise, no teacher enjoys recording poor grades in his or her grade book. Both students and teachers want to minimize the chance of things going wrong with the student learning process. In other words, they would like the student learning process to become a more reliable one.

Increasing the reliability of the student learning process is a special case of the more general problem of improving the reliability of a service process. While the issue of service reliability has been gaining attention in the literature, only a few research papers have examined how to apply technical reliability tools in actual service contexts (Hensley and Utley, 2011). Furthermore, these research papers tend to narrowly focus on tools implemented in service subsystems while ignoring system wide consequences of poor reliability (Song, Lee and Park, 2012). Needed are analytical frameworks for process reliability that combine systems thinking with technical tools for reliability improvement. This paper develops one such framework that can be used to improve the reliability of the student learning process. In this framework, reliability is defined as the capability of the process to meet specified requirements within a given time frame. (Burtescu, 2010, Gunes and Deveci, 2002) This definition implies that the process can be made more reliable over time if mistakes can be reduced by addressing the causes the led to these mistakes (Burtescu, 2010, Galetzka, Verhoeven and Pruyn, 2006; Parasuraman, Zeithaml and Berry, 1985). As Madu and Kuei (1993, p. 336) note, "The objective in the classroom is not to detect errors at the end of the semester, but rather to prevent errors from occurring."

This paper is organized as follows. Section 2 will review the literature that supports the reliability improvement framework devised by the authors. This framework involves four stages: systems modeling, problem identification, problem correction and impact on process improvement. Section 3 will apply the framework within an actual student learning context. Specific problems identified by the proposed methodology will be delineated. Solutions implemented in response to the problems will also be presented. Section 4 will discuss the implications of the application results. The concluding section will delineate possible limitations of the proposed framework and will provide suggestions for future research. 


\section{Literature Review}

In the student learning process, as in other service processes, reliability improvement directly supports quality (Gunes and Deveci, 2004, Kuei and Madu, 2003; Madu, 1999, Madu and Kuei, 1993). The relationship between reliability and quality is so strong that a number of researchers have abandoned the view that reliability is simply a component of quality and have instead equated the two. For instance, Sun, Xi, Ju and Du (2008, p. 152) define reliability as "quality over time" while Madu (2005, p. 319) argues that "quality and reliability are intertwined and it is often difficult to draw the line" between them. Viewed from this perspective, reliability improvement encompasses quality improvement. Consequently, it is possible to model the reliability improvement process as an extension of the quality transformation cycle devised by Dr. Shewhart (Deming, 1986) and popularized by Dr. Deming. Madu and Kuei (1995) accomplished this when they recast Deming's plan-do-check act cycle as a strategic reliability cycle. Similarly, Madu (1999) utilized SWOT analysis as the starting point of a reliability improvement cycle based on the Deming Wheel.

Since the models proposed by Madu and Kuei (1995) and Madu (1999) emphasize organizational strategic planning as the initial step in reliability improvement, they are not readily applicable to student learning processes. Moreover, quality improvement studies in education that simply mirror the Deming cycle do not incorporate formal systems modeling. For instance, Daniels' (2006) study reports that an Oklahoma school district began its improvement process with goal setting. Systems modeling constitutes a critical initial step in reliability improvement because process errors result when systems thinking does not take place (Kuei and Madu, 2003; Madu, 1999). As Figure 1 shows, the proposed framework recognizes the importance of systems thinking as the initial step in reliability improvement.

The first stage in the framework involves a systems approach of the student learning process. A systems approach requires a model that captures all major components of the learning process and their inter-relationships. The systems perspective outperforms a piecemeal approach to improving reliability which can generate counter-productive measures that may waste time, effort and money (Sulek and Hensley, 2010; Testa and Snipe, 2006). The service management literature contains several systems models of quality and reliability (Sulek and Hensley, 2010; Lusch, Vargo and O'Brien, 2007; Stewart, 2003, Chase and Bowen, 1991). This paper will utilize the 3T model devised by Stewart (2003) because its emphasis on component inter-relationships makes it well suited to the learning process.

Stewart's (2003) model identifies three important system components: tangibles, treatment and task. The tangibles component refers to the physical properties of the service context. The treatment component involves the emotional/social environment in which the process occurs. The task component represents the essential activity that must be completed by the end of the process. Stewart (2003, p. 255) notes that the 3 T's "do not merely form complementary parts of the service experience, but rather, they serve as mutually supporting aspects of the service experience, each capable of offsetting to some extent, weakness in the others. "One can readily apply the $3 \mathrm{~T}$ model to the student learning process.

The tangibles component includes the physical setting in which teaching and learning occur. Tangibles may not be changeable in the short-term since they typically result from long-term design. Examples include the layout of the classroom (size and shape of the room, boards, computer equipment, configuration of the desks), elements of the service environment (comfort of seating, temperature, lighting) and how the professor and students move about in the classroom.

The treatment component involves the social interaction between the student(s) and the professor. Treatment encompasses both the one-to-one relationship between the professor and student and the relationship between the class and the professor. A student may use a variety of terms such as empathy, friendliness, willingness to listen, accessibility, trust, assurance and respect to describe a positive relationship with the teacher. Treatment occurs in the classroom and can also occur outside the classroom in both physical settings (such as office hours) and virtual settings (such as e-mail communications).

The task component deals with the activities that are needed to achieve specific learning goals within a specific time frame. Stewart (2003, p. 249) notes that the task component "is primarily active rather than physical in nature." The task component facilitates a transformation from an initial state to the desired outcome state. In the student learning process, one should be able to clearly delineate the elements that comprise the task component(Lam and Zhao, 1998).

After the systems modeling of the student learning process is completed, the next step in improving reliability is problem diagnosis. There are a number of technical tools from which to choose to complete this step; however, 
Pareto analysis and statistical process control charts are especially well suited to the student learning process (see Hensley and Utley (2011) and Madu (2005) for discussion of other reliability tools that may be applied to service operations).

Madu (2005, p. 321) notes that in any process "most of the reliability problems can be explained by a few causes. This has a significant impact in managing reliability since it enables us to focus on the few causes that can potentially influence system or process reliability. "Pareto analysis has been widely used in practice to identify the major causes of problems and errors in a process (Hensley and Utley, 2011; Madu, 2005; Wyckoff, 1984). In a student learning process Pareto analysis can reveal the few significant causes of poor student performance. It is important to be able to quickly identify the key causes of error because the student learning process is constrained by rather tight time limits, especially in courses - like quantitative methods classes - where knowledge is cumulative (Madu and Kuei, 1993).

Statistical process control chart use also supports the problem diagnosis step. Control charts indicate whether or not a process is predictable within limits or, in other words, operates in a state of statistical control (Deming, 1986). A lack of predictability means a lack of reliability (Madu, 1999). Identification and removal of the special causes of variation that cause the chart to go out of control may help to eliminate problem sources in the student learning process (Yoshida, 1994). In some instances, a chart may go out of control due to unpredictably high process performance (Marks and O'Connell, 2003). When this happens, identifying the source of the unnatural variation may uncover ways to improve student learning.

Effective use of control charts to monitor the learning process requires careful selection of process data and control charts. First, data used in the charts must be plotted in a natural time-ordered sequence (Western Electric, 1956). Lack of a natural time ordering in the data defeats the purpose of the chart, which is to assess the predictability of the process within limits. Second, the data must be suitable for the type of chart that is constructed. For instance, the use of categorical survey data (as are gathered in course evaluation surveys) with $\mathrm{x}$ charts is problematic since normality assumptions are not met (Ding, Wardell and Verma, 2006). Finally, the organization of data into subgroups must match the structure that exists in the data. Failure to do this will inflate variation within the subgroups, which can lead to unreliable control limits (Wheeler and Chambers, 1992).

Stage three of the reliability framework involves process correction. One of the most direct ways to achieve this objective is to adopt fail-safe solutions tailored to the process context. In a student learning process failsafe solutions encompass techniques and devices that help students prevent or quickly correct errors that degrade learning performance. Failsafe solutions need not be complicated (Chase and Stewart, 1994). For example, a simple e-mail reminder to attend a team meeting could prevent a student from missing an important discussion about a team project.

The final stage shown in Figure 1 involves assessing the impact of problem correction to support continuous process improvement. Wheeler and Chambers (1992, p. 152) have observed that "one can rarely leap from current conditions to the ultimate process potential." They argue that one must instead persevere in trying to understand the process. In a student learning process this requires the involvement and commitment of everyone who teaches a particular course to make the incremental improvements - such as the failsafe solutions from stage three - that can raise performance levels. It is equally important to determine the effectiveness of the failsafe solutions and to candidly assess the need for possible systemic changes in course delivery (Deming, 1986). Such changes entail a re-examination of the systems model, which is the starting point of another cycle of reliability improvement.

The reliability framework proposed in this section is a general one that may be applied in a variety of learning contexts. The following section illustrates how this framework was implemented in an actual class setting in a school of business.

\section{Methodology}

A Management Science class taught in an AACSB-accredited school of business located in the Southeast United States served as the application context for the proposed reliability framework. The Management Science course was a required course for all undergraduate business majors. The forty-nine students in this study included 24 women and 25 men. Twenty-four were Management majors; eleven were Marketing/Supply Chain majors; seven were accounting majors; five were finance majors and two were Business Education majors. Seven students were Seniors and the remaining students were Juniors. The purpose of the course was to introduce students to quantitative modeling for business decision making, with an emphasis on the formulation, solution and interpretation of linear programming models - including continuous variables models, all-integer linear programs and mixed-integer linear 
programs. The key activities on which students were graded included: 1) a team research project, 2) in-class participation and presentation of homework, 3) three tests, 4) case presentation, 5) a final exam and 6) a formal assessment of learning.

The authors utilized qualitative and quantitative data to examine the student learning process in this course. Application of the reliability framework proceeded in the following stages:

\subsection{Stage 1: Systems Thinking}

The student learning process was analyzed using the $3 \mathrm{~T}$ framework. The analysis revealed some limitations as well as opportunities to utilize supporting relationships among components.

Results of the systems modeling revealed that the tangibles component of the 3T model is somewhat constrained by the design of the classroom in which the course is taught. The classroom is relatively new and contains an equipment console that houses projection equipment and a computer with access to the Internet and Microsoft Office products. In particular, Microsoft Excel and Solver are available for demonstrating computer solutions to the linear programming models. The basic shape of the classroom is rectangular with the teacher's equipment console at the front of the room. At a few of the desks students have a slightly blocked view of the whiteboard due to an enclosed heating duct near the board and to the computer monitor on top of the equipment console. Since there is only one computer in this room, students do not have personal access to Solver software during class unless they bring their own laptops to class. The teacher encourages them to do so and explains how to add on Solver software during class time.

Although the course material may at times appear somewhat intimidating to students, the professors do not. Results from student reviews of teaching and from peer reviews of teaching reveal an atmosphere of helpfulness, empathy and concern both in class and out of class. During office visits students receive additional help with the Solver modeling and solution process. These visits also give students ample opportunity to work through homework problems and to discuss any other aspects of the course of interest to them. Thus, the emotional/social environment during office visits, which is part of the treatment component, helps to compensate for limitations in the tangible aspects of the learning process (i. e. , lack of in-class computers for the students and limited sight lines at a few of the seats in the class room).

The task component involves a set of activities that help students understand linear programming. For simplicity, the authors will confine the discussion of the task to three required activities: 1) in-class participation, 2) the team research project and 3) the formal assessment of learning.

Since the course material is at times quite technical, the class is taught in a highly interactive manner. As new material is presented, students are encouraged to ask questions and to respond to the teacher's questions to gain a deeper understanding of the material. Discussion is critical to helping students develop their problem solving skills. (Lam and Zhao, 1998)As mentioned earlier, students receive daily participation points based on contributions to class discussion, for putting homework on the board or for presenting Solver reports using the document camera or computer. Participation points for each student were recorded every day, except for exam days.

The team project required students to formulate a linear program, solve it with Excel Solver, interpret the results and discuss the managerial implications of their work. The project took an entire semester to complete. Each team made a formal presentation near the end of the semester and also turned in a written technical report. Historically, this project could prove to be a major stumbling block to students who had failed to master formulation or the details of Solver solution and interpretation.

For AACSB assessment of learning purposes, the Management Science class was also tested using an assessment instrument developed by the Management Science faculty. The assessment instrument included three parts:(1) four questions related to formulation and graphical solution, (2) five questions related to interpretation of Excel Solver reports and (3) one short essay related to interpretation of dual prices and right hand side ranges. As the following sub-section will illustrate, the results from this assessment helped to reveal problem areas in the student learning process.

\subsection{Stage 2: Diagnosis of Problems}

Since this class featured a highly interactive format and demanding mathematical material, student participation was essential. As stated earlier, students earned points by participating in class discussions and by presenting homework problems. Individual point totals were aggregated on a daily basis to produce a daily total of participation points for the entire class. The first twenty daily totals for one class were used to devise an x-chart, which is also known as the 
chart for individual measurements. This type of chart is used when there is "only one number to represent a given condition" (Western Electric, 1956, p. 21). In practice, this chart is may be used to monitor "accounting figures of all kinds, including shipments, efficiencies, absences, losses, inspection ratios, maintenance costs, accident reports" and similar measures (Western Electric, 1956, p. 21).

The $\mathrm{x}$ chart uses the average of the individual values (or x's) as the centerline. In this case the average was 21.45 points. The upper and lower limits are computed by first calculating two-period moving ranges for the differences between consecutive individual values. These moving ranges are then averaged (there will be one fewer observations than in the original data) to provide the average of the moving range $(M \bar{R})$. The computed $M \bar{R}$ was 9.105263 points. The $M \bar{R}$ is then multiplied by 2.66 to obtain the amount to be added to and subtracted from the centerline (24.22) to produce the upper control limit (UCL) and the lower control limit (LCL) for the x chart (Western Electric, 1956, p. 22).

$$
\begin{aligned}
M \bar{R} & =9.105263 \\
(2.66) M \bar{R} & =24.22 \\
U C L & =21.45+24.22=45.67 \\
L C L & =21.45-24.22=-2.77 \Leftrightarrow 0
\end{aligned}
$$

As Figure 3 shows, the chart goes out of control on day 11. This signals an unusually high degree of participation by the class as whole. During this class students had the opportunity to present homework which consisted of corrected solutions to problems from the first test.

Pareto Analysis of the assessment of learning results revealed that there was a pattern in the missed questions on the assessment (Figure 2). As Figure 2 shows, the most common problem was an incorrect interpretation of the right hand side analysis found in the Solver Sensitivity Report. This question accounted for $23.6 \%$ of the mistakes on the assessment. Incorrect interpretation of the range of optimality generated $16.4 \%$ of the errors; graphing mistakes amounted to $15.7 \%$ of the errors. Mistakes on interpreting the optimal solution comprised $13.6 \%$ of the errors while mistakes on reading the optimal solution accounted for $12.1 \%$ of the errors. Problems related to model formulation accounted for $9.3 \%$ of the mistakes. Incorrect answers to questions dealing with the slack/surplus values on the Solver Answer Report also contributed to $9.3 \%$ of the mistakes. These findings suggested that potential difficulties loomed with the technical reports and presentations required by the team research projects.

\subsection{Stage 3: Process Correction}

The results from stage 2 were used in conjunction with the systems model to produce several failsafe solutions. The results of the $\mathrm{x}$ chart analysis of daily class participation revealed that students valued the opportunity to gain additional points while correcting their answers to test questions. By correcting their mistakes on the tests, students gained insight on the kinds of mistakes they had made. By listening to students explain correct solutions, the class got another chance to understand the complexities of the material. Clearly, this technique is one that should be maintained to raise class participation.

The Pareto analysis showed that students had the most difficulty interpreting the Solver Sensitivity Report when completing the assessment of learning tool. Several failsafe solutions were developed. First, students were given an additional homework assignment that dealt with Solver report interpretation and additional class time was spent discussing the solutions to this assignment. Second, a series of progress reports for the team linear programming project were devised, with one report focused on the Excel model and the Answer and Sensitivity reports. The team captain completed the reports in conjunction with team members. On each report, the team captain was asked to comment on team dynamics and to report any problems with team cohesion. Third, the due date for the final progress report was set two weeks before the project was due to ensure that students who were having trouble with the Solver reports could receive additional assistance, particularly during office hours.

\subsection{Stage 4: Continuous Improvement}

The failsafe solutions devised in stage 3 were aimed at repetition of key concepts, in-class discussion and timing. These solutions constituted constructive attempts at reliability improvement in this class.

The control chart analysis revealed that class participation increased greatly when students presented their test corrections. Since high in-class participation is desirable in this learning context, this failsafe solution could be used again in this class. 
The extra homework assignment on Solver solution and the deadlines on the team progress reports enabled students to accelerate their work on the Solver model and its interpretation. In fact, some student teams finished this portion of their project earlier than expected. These teams tended to meet frequently outside of class and many participated in multiple meetings with the professor during office hours. The accelerated pace and the re-enforcement of Solver concepts resulted in solid performance by these students on Solver-related questions on final project presentations. While some teams clearly benefited from the failsafe solutions, others did not perform as well. These teams appeared to have some difficulties with team dynamics, even though they failed to address these problems in their progress reports. Thus, better monitoring of team dynamics is one area for future improvement.

\section{Discussion}

Implementation of the reliability framework shown in Figure 1 leads to several practical implications. These include flexibility, failsafe solution design and extent of systemic change.

The reliability framework is a flexible one because it allows the inclusion of a variety of reliability tools in addition to Pareto analysis and the $\mathrm{x}$ chart. For example, root cause analysis may be conducted to determine why students failed to achieved a targeted performance level on a particular learning assessment. Similarly, other types of control charts could be implemented. For instance, the $\mathrm{c}$ chart, a special kind of control chart for attributes data might be utilized. The c chart controls for the number of defects produced within a product where a defect is defined as "an individual failure to meet a single requirement" (Western Electric, 1956, p. 20). The c chart is appropriate for analyzing complicated products in which the number of opportunities for defects "approaches (for practical purposes) an "infinite" number of possibilities" (Western Electric, 1956, p. 20). Thus, the number of mistakes on daily quizzes could be analyzed with a c chart.

A second practical implication of the framework deals with the design of the failsafe solutions. Since the purpose of a failsafe technique is to help correct a specific problem with the process and hopefully prevent the error from re-occurring, it is important to tailor the failsafe solution to the particular problem that is observed. For example, in the application context, a new homework assignment was created to address the problem of right hand side interpretation of linear programming results. Although a specific problem on a formal, scheduled assessment prompted this failsafe solution, some failsafe solutions occur more spontaneously. Failsafe devices can be devised and implemented whenever the need arises. Thus, the style and number of failsafe solutions tend to vary with the learning context.

A final practical implication deals with the degree of systemic change that occurs with each cycle through the framework. As failsafe solutions are implemented, some changes to the student learning process may occur. For instance, the permanent inclusion of an additional assignment such as the one targeting Solver right hand side analysis slightly alters the task component in the systems model. Similarly, allowing students to present test corrections resulted in an out of control observation on in-class participation. This is significant because it represents a solution that increases participation scores in general and re-directs student focus to finding and correcting his or herown mistakes. Thus, the student becomes an active participant in error reduction before the end of the semester, as suggested by Madu and Kuei (1993).

Of course, one may not be able to address all problems with failsafe techniques alone. For instance the classroom design problems described earlier will require a major change to the tangibles component to fix completely. Similarly, replacing the Solver software with alternative linear programming software constitutes a major systemic change. These kinds of changes cannot be made by a single professor but rather require the involvement and consent of colleagues and/or administrators.

\section{Conclusions}

The purpose of this paper was to develop and illustrate a reliability framework for the student learning process. Although the framework is flexible and can be used to address both special causes of variation and common causes of variation in the student learning process, two possible problems with the framework implementation may arise in practice. These deal with the willingness of the instructor to use the framework and the additional time involved in constructing and implementing the framework.

The framework was illustrated in a business school context; however, in other contexts, the framework may seem complicated and simply not worth the trouble. For instance, instructors in a dance department might complain that they have no training in statistical process control and may reject the framework on those grounds alone. Since the framework permits flexibility in the choice of reliability tools, more intuitive tools like fishbone diagrams and Pareto analysis might be used instead. In other application contexts teachers might be wary of the additional time required 
to implement the framework. However, if the framework is presented as a continuous improvement plan, faculty may be more receptive to its implementation, particularly when used to facilitate accreditation/re-accreditation efforts.

The framework presented in this study was implemented in a school of business. Future research could address its implementation in other learning contexts. In addition, the use of other types of reliability tools could be examined. This should not prove too difficult to execute in practice since the framework illustrated in this study is a flexible one and does provide a structured approach to improving the reliability of the student learning process.

\section{References}

Burtescu, E. (2010). Reliability and security - convergence or divergence. Informatica Economica, 14(4): 68-77.

Chase, R. B. \& Bowen, D. (1991). Service quality and the service delivery system: a diagnostic framework. in Brown, S. , B. Evardsson, B. and Gustavsson, B. (Eds. ), Service Quality: Multidisciplinary and Multinational Perspectives. Lexington MA: Lexington Book, (157-178).

Chase, R. B. \& Stewart, D. (1994). Make your service failsafe. Sloan Management Review 35(3): 35-44.

Daniels, S. (2006). Oklahoma school district goes over the top. Quality Progress, 39(5):51-59.

Deming, W. E. (1986). Out of the Crisis. Cambridge MA: MIT Press.

Ding, X. , Wardell, D. \& Verma, R. (2006). An assessment of statistical process control-based approaches for charting student evaluation scores. Decision Sciences Journal of Innovative Education, 4(2): 259-272. http://dx.doi.org/10.1111/j.1540-4609.2006.00116.x

Galetzka, M. , Verhoeven, J. W. M. \& Pruyn, A. Th. H. (2006). Service validity and service reliability of search experience and credence services: a scenario study. International Journal of Service Industry Management, 17(3): 271-283. http://dx.doi.org/10.1108/09564230610667113

Gunes, M. \& Deveci, I. (2002). Reliability of service systems and an application in student office. International Journal of Quality \& Reliability Management, 19(2): 206-211.

Hensley, R. L. \& Utley, J. S. (2011). Using reliability tools in service operations. International Journal of Quality \& Reliability Management, 28(5): 587-598. http://dx.doi.org/10.1108/02656711111132599

Kuei, C-H. \& Madu, C. N. (2003). Customer-centric six sigma quality and reliability management. International Journal of Quality and Reliability Management, 20(8/9): 954-964. http://dx.doi.org/10.1108/02656710310493661

Lam, K. \& Zhao, X. (1998). An application of quality function deployment to improve the quality of teaching. International Journal of Quality \& Reliability Management, 15(4): 389-413. http://dx.doi.org/10.1108/02656719810196351

Lusch, R. F. , Vargo, S. L. \& O'Brien, M. (2007). Competing through service insights from service-dominant logic. Journal of Retailing, 83(1): 5-18. http://dx.doi.org/10.1016/j. jretai.2006.10.002

Madu, C. N. (1999). Reliability and quality interface. International Journal of Quality \& Reliability Management, 16(7): 691-698. http://dx.doi.org/10.1108/02656719910286198

Madu, C. N. (2005). Strategic value of reliability and maintainability management, International Journal of Quality and Reliability Management. 22(3); 317-328. http://dx.doi.org/10.1108/02656710510582516

Madu, C. N. \& Kuei, C. (1993). Dimensions of quality teaching in higher institutions. Total Quality Management, 4(3): 325-338. http://dx.doi.org/10.1080/09544129300000046

Madu, C. N. \& Kuei, C-H. (1995). Strategic Total Quality Management. Westport CT: Quorum Books.

Marks, N. B. \& O'Connell, R. T. (2003). Using statistical control charts to analyze data from student evaluations of teaching. Decision Sciences Journal of Innovative Education, 1(2):259-272. http://dx.doi.org/10.1111/j.1540-4609.2003.00020.x

Parasuraman, A., Zeithaml, V. A. \& Berry, L. L. (1985). A conceptual model of service quality and its implications for future research. Journal of Marketing, 49(4): 41-50. http://dx.doi.org/10.2307/1251430

Song, B. , Lee, C. \& Park, Y. (2012). Assessing the risks of service failures based on ripple effects: a bayesiannetwork approach. International Journal of Production Economics, forthcoming: http://dx.doi.org/10.1016/j.ijpe.2011.12.010

Stewart, D. M. (2003). Piecing together service quality: a framework for robust service. Production and Operations Management 12(2): 246-265. http://dx.doi.org/10.1111/j.1937-5956.2003.tb00503.x 
Sulek, J. M. \& Hensley, R. L. (2010). Updating service operations. Managing Service Quality, 20(5): 475-489. http://dx.doi.org/10.1108/09604521011073759

Sun, J. , Xi, L. , Du, S. \& Ju, B. (2008). Reliability modeling and analysis of serial-parallel hybrid multi-operational manufacturing system considering dimensional quality, tool degradation and system configuration. International Journal of Production Economics, 114(1): 149-164. http://dx.doi.org/10.1016/j.ijpe.2008.01.002

Testa, M. R. and Snipe, L. J. (2006). A systems approach to service quality, Cornell Hotel and Restaurant Administration Quarterly. 47(1): 36-48. http://dx.doi.org/10.1177/0010880405279173

Western Electric Co, Inc. (1956). Statistical Quality Control Handbook. Charlotte NC: Western Electric Co, Inc.

Wheeler, D. J. \& Chambers, D. S. (1992). Understanding Statistical Process Control, $2^{\text {nd }}$ Edition. Knoxville, TN: SPC Press.

Wyckoff, D. D. (1984). New tools for achieving service quality. Cornell Hotel and Restaurant Administration Quarterly, 25(3): 78-92. http://dx.doi.org/10.1177/001088048402500317

Yoshida, K. (1994). The Deming approach to education: a comparative study of the USA and Japan. The International Journal of Educational Management, 8(5): 29-40. http://dx.doi.org/10.1108/09513549410065738

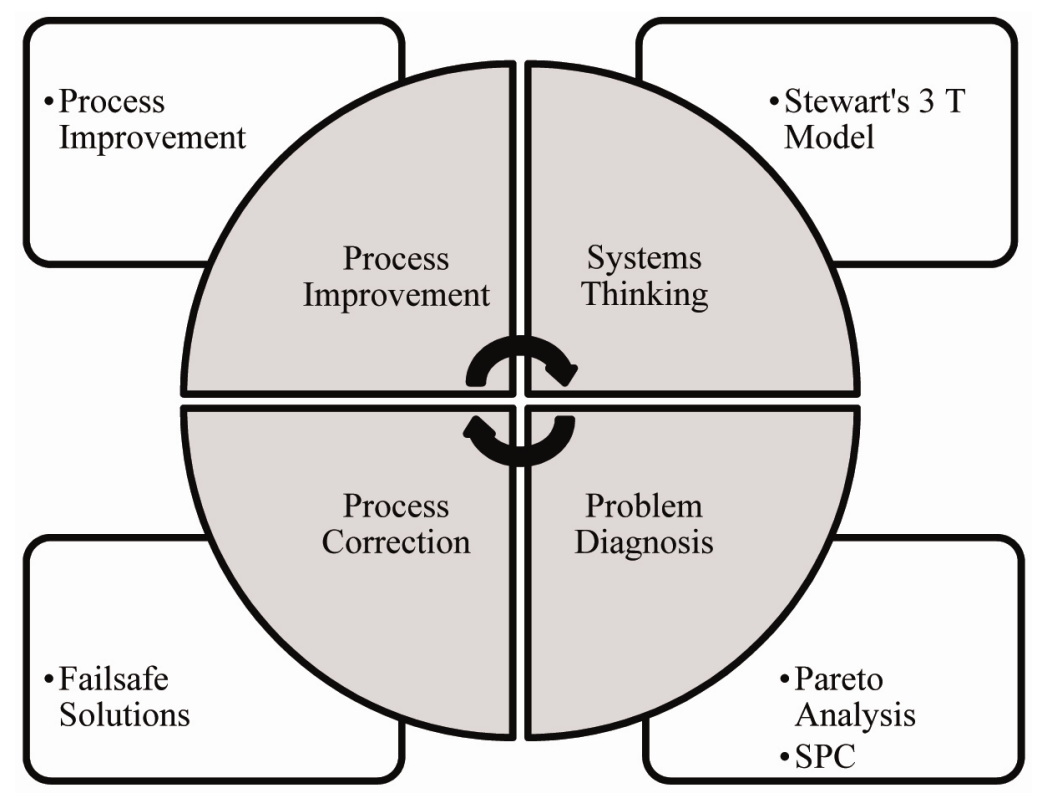

Figure 1. Framework 


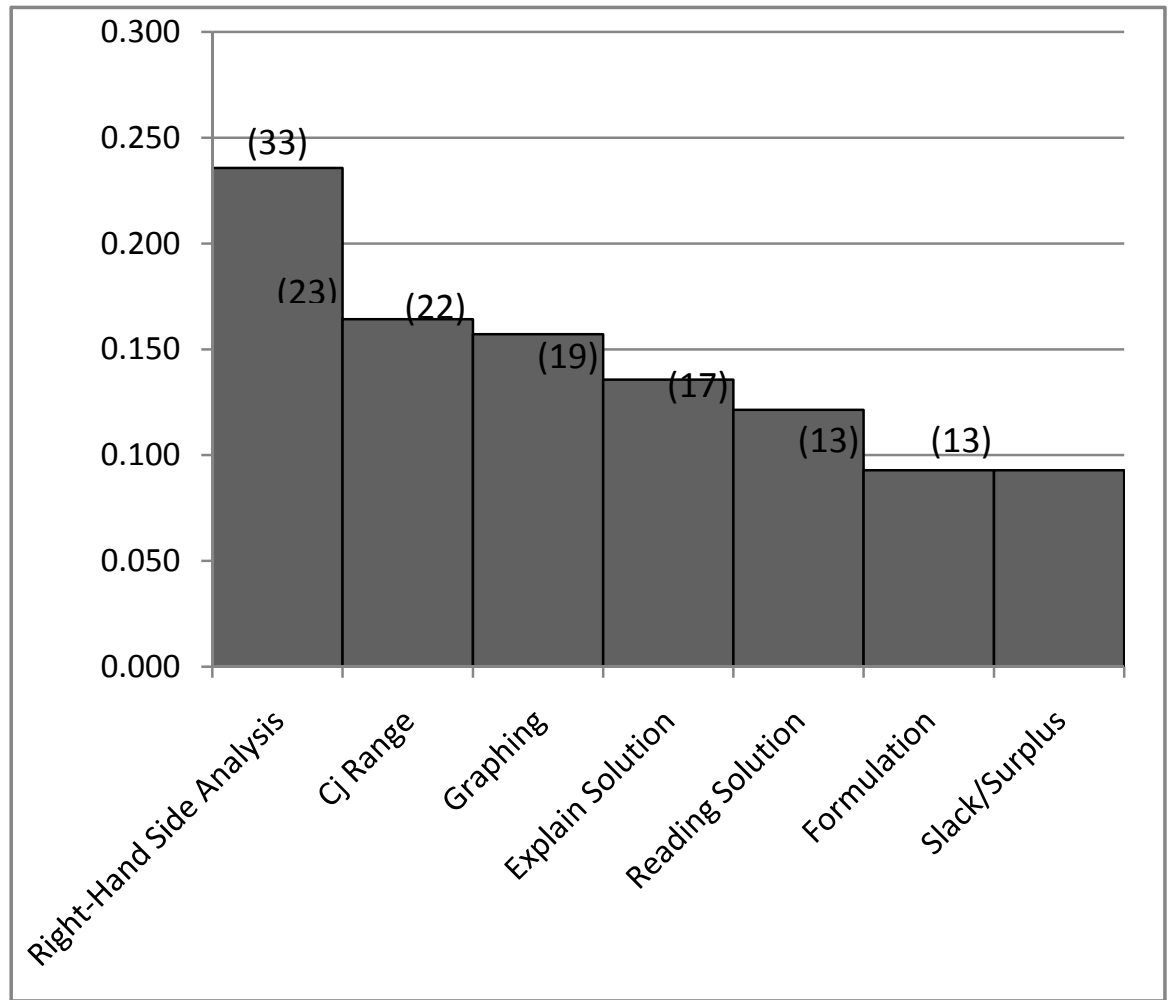

Figure 2. Pareto Analysis

$(n=$ total number of errors $=140)$

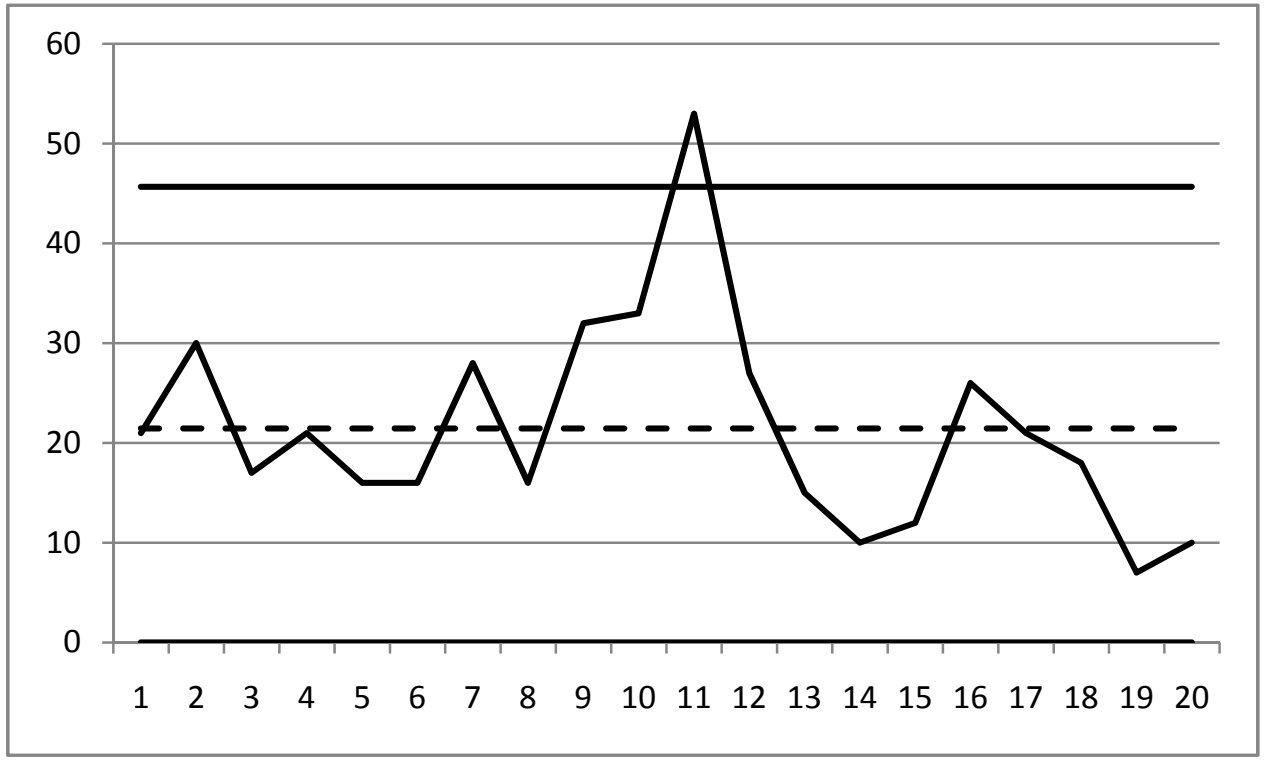

Figure 3. x Chart 